may perhaps be made use of in determining the height of the meteor above the earth's surface.

When I first saw the meteor, it was passing, I should say, through the constellation Leo Minor. I am confident that it passed a little east of Beta Leonis Majoris, say three degrees, and I think that it passed east of Gamma Virginis, near which it disappeared. While passing between these two stars, it emitted two flashes of brighter light, - white or somewhat bluish. Its motion was slow.

Dorchester, Mass., June 21.

J. R. W.

\section{Museums of ethnology and their classification.}

The article of Dr. Boas, to which you call attention in your note to myself, treats of two distinct subjects: first, the interpretation of similarities; and, second, the best method of grouping archeological objects in the museum. In Professor Mason's report the same subjects are discussed. The interpretation question has but a very remote connection with the museum question, and as I have already discussed it somewhat at length in the 'Third annual report of the bureau of ethnology,' under the head of 'Activital similarities,' I think I may well neglect that subject in this short communication.

The functions of a museum are twofold : first, as a repository of materials for the investigator ; second, as an objective exemplification of some system of knowledge pertaining to the subject for which the collection is made, to be used by an instructor with his pupils, and as an exhibition of facts for the passing observer who visits the museum.

The first purpose is of prime importance : the history of museum administration abundantly develops this fact, and more and more is its value understood. It is in this manner that great museums make substantial contributions to science, and increase the knowledge of the world. The successful management of a museum for this purpose involves the study of museum cases and various other appliances and devices, together with museum records, descriptive catalogues, etc. In the performance of this function the methods and appliances of the national museum are of the highest excellence, but it would require a volume to fully set them forth. Professor Baird, one of the greatest organizing minds of the scientific world, has devoted a large part of his life to this subject.

The secondary use of a museum, mentioned above, somewhat interferes with its primary use; and because it is secondary it must not be allowed to interfere with the more important function. In a great museum like that at the national capital, the collections are so vast that the public exhibition of them all is impossible : only a very small per cent can be shown with reasonable expenditure. This being the case, the secondary use interferes with the primary use only to that limited extent. A few selections are made to be shown to the public: the great mass of material is kept ready to do service for the investigator. Therefore, with regard to the arrangement of the materials for the museum for public exhibition, the question is narrowed down to this : first, on what principles shall the selections be made? and, second, in what order shall they be arranged? That is, the administrator of the museum is called upon to determine what is the most useful lesson to the gen- eral public which his materials can be made to teach. Every investigator will be more or less likely to consider his own subject of prime importance, as it is to himself; and every instructor is, in like manner, likely to consider that his system of instruction is of prime importance. As research progresses, one set of problems after another comes to the front, and is for the time being of chief importance. For such reasons the nauseum appliances for exhibition should be of an easily adjustable kind. No sound philosophic scholar, be he investigator or instructor, will assert that his own system is complete and final, that any classification or arrangement is ultimate. It is in view of these facts that the authorities of the national museum have devoted their efforts very largely to methods of exhibition, to the consideration of cases, trays, stands for mounting, etc., so as to have the parts interchangeable and easily readjusted to new conditions, - new facts arising from the advance of the science and from the enrichment of the collections; and it seems to me that many problems involved have been very satisfactorily solved. The actual exhibition portion of the collection in the national museum has not been put into permanent shape. What has been done has been experimental and tentative. The arrangement at one time may be very different from that of another; and this is rendered easy and inexpensive by reason of the system above described.

Now, Dr. Boas offers a system or plan for the arrangement of the materials which relate to the preColumbian peoples of America and their descendants. He would have them arranged by tribes. On the discovery of America there were probably many more than twenty-five thousand tribes inhabiting the country, each a little band of people organized into a body-politic, and autonomous, at least for all domestic purposes. But probably within the first year, changes were made in some of these bodiespolitic: some coalesced by treaty or conquest, others divided through disagreement, individuals from some tribes took up their abode and became incorporated with other tribes: and so, by various methods from time to time, all of these bodies-politic were in a flux; so that a hundred years after the discovery of America it is not probable that there existed any one tribe which could claim to be the pure and simple descendant, without loss, admixture, or change, of any tribe existing at the time of the discovery. These changes have been going on more and more rapidly until the present time, and they are still going on. Most of the tribes best known to history have been absorbed, consolidated, and redivided again and again. Now, this means simply that under primitive and under modern conditions alike there has been no permanent tribal organization, - a body-politic whose history can be followed as that of one people by hereditary descent. A museum collected to represent the tribes of America, therefore, to be properly representative, would have to be collected as the census of the native inhabitants of India has been taken, all in one day, by an army of collectors. Collected in any other way, it would have no proper significance; and collected in the manner suggested, it would have very little scientific value.

But if a classification of the tribes of North America were possible, the archeologic collections actually made in the country could not be relegated to them, for the tribes have been forever migrant. 
The materials are derived from a variety of sources, which may be briefly enumerated as follows. First, those taken from the mounds. But we now know that many tribes have erected mounds, and ofttimes the same mounds have been occupied by different tribes belonging even to different linguistic stocks. Only a few mounds have been or can be relegated to the Indians who built them. Second, another class of materials has been found in stone graves, ossuaries, and other burial-places; but it is rarely the case that these burial-places can be referred to the specific tribes that used them. Third, much of the material is distributed on the surface of the earth, and picked up in woods, fields, caves, etc.; but it is very rarely indeed that any of this material can be referred to specific tribes. Then there is a vast body of material in the ruins of the arid regions of the west, very little of which can be relegated to specific tribes. Again, collections have been made from time to time, in the years and centuries past, from the Indians themselves; but as these tribes have been ever changing, as heretofore remarked, and as the names of tribes change from time to time, so that the synonymy is exceedingly complex and difficult, the same names being used for different tribes, and the same tribe being known by different names, there is no historical collection of any magnitude in the land that could with confidence be affirmed as coming from definite, specified tribes. Again, very many of the articles which are brought together in a large archeologic museum are the materials of barter from tribe to tribe. This barter has been on a scale so extensive, that, if there were no other difficulties in the way of determining the inventors and makers, this would be sufficient to cast a doubt upon nearly all collections made. There is yet another source that contaminates much of the material collected, and puzzles the student of archeology to the highest degree. Stone implements, shell ornaments, copper implements, utensils, etc., were, in the early history of the country, manufactured on a large scale by traders, to be bartered with the Indians for peltries. A vast amount of this material was thus manufactured; and, because it was more or less superior to the work of the Indians themselves, it intrudes its way before all other objects into the collections of the country.

It will be seen, that, taking all things together, a tribal arrangement of the archeologic museum of North America is an impossibility by reason of its nature.

But the tribal museum as suggested by Dr. Boas would, in practical affairs, be an impossibility by reason of its magnitude. In the many thousand groups of which it would be composed, the objective material would be duplicated over and over again, and to the observer would be monotonous and meaningless.

But may not the tribes be classified? The socalled 'ethnic' classifications of mankind have usually been based upon physical characteristics, found in the relative proportions of the parts of the body, which has led to a high development of anthropometry; in the characteristics of the cranium, which has led to a high development of craniology ; and in the color of the skin, the texture of the hair, the attitude of the eyes, etc.; but no thorough classification of mankind on these characteristics has ever been established. This only has been done: a greater or less number of varieties have been de- scribed as types ; but, whenever the attempt has been made to relegate the peoples of the world to these varietal types, the task has been found impossible. Mankind cannot be classified into races thoroughly inclusive and exclusive. Very much more has been done in the classification of languages; but this furnishes a very imperfect classification of peoples. In fact, it does not properly mean an ethnic classification. I know of no attempt to classify mankind by arts, or by institutions, or by opinions, worthy of the mention; yet arts may be classified, institutions may be classified, and opinions or philosophies may be classified, but the results thereof are in no proper sense a classification of peoples.

In this connection it is sufficient to say, that, as there is and can be no ethnic classification of the tribes of America, so there can be no classification of their arts on that basis. Yet we might classify their arts in a museum on the basis of classes derived from linguistic affinities ; but it would be wholly arbitrary, and lead to no valuable results. The Paiutes of Utah, the Comanches of the plains, and six of the Pueblos of New Mexico, that are called by the bureau of ethnology the 'Shinumos,' and included in the ancient province of Tusayan, all belong to the same linguistic family; but their arts are most diverse, as will readily occur to any one familiar with the subject. The Apaches of Arizona and New Mexico would be thrown into a group with the Tinne Indians in the region of Lake Athabasca. And like illustrations might be extended to an indefinite length.

Dr. Boas suggests a geographic distribution in a manner which makes it appear that he considers a geographic classification to be essentially the same as an ethnographic classification, but the two are altogether different things. It is said that prairiedogs, owls, and rattlesnakes successively occupy certain underground habitations on the plains, but they are not thereby classed as one group in systematic zoölogy; and he who supposes that the multifarious tribes in one region of America are of the same stock, or can in any proper way be classified as one, has failed to understand the ethnology of the American races. But this leads to the consideration of a classification by geographic provinces, as advocated by Bastian and referred to by Boas. If the primary classification of the museum should have this basis, some very interesting facts would be presented. It is well known that zoölogic provinces and botanical provinces have been defined by various biologists, and the facts connected therewith are of great interest. In like manner the art provinces of North America are of great interest. To this subject the bureau of ethnology, under my charge, has given much attention, and gradually we are reaching some interesting results; and at the present stage of this research, if we could have a grand museum arranged on this basis, investigations would be made with greater ease, and perhaps facts and ideas would be suggested which will not be discovered in the lack of such a grand museum. Yet I should hesitate to affirm that that was the best arrangement for the national museum or any other great collection.

The human activities which characterize mankind may be classed as arts, institutions, languages, and opinions or philosophies. Of these activities, the arts only can be represented in a museum, and they but in part. An anthropological museum, therefore, 
is an impossibility; but we may have a museum of arts, including the arts industrial and aesthetic. But, while such a museum might be possible, it is impracticable, for a collection of the arts of all peoples of all times would be of such magnitude that it could not properly be made and preserved within practical conditions of economy. That which the great institutions of the world really attempt is an archeological museum, - a museum of the antiquities of the higher races, and of the past and present of the lower races. In the administration of such a museum it may be considered best to segregate a part thereof for exhibition, as indicated in a previous part of this letter; but their arrangement by tribes on ethnic characteristics of any kind is an impossibility. Their arrangement by geographic districts is possible, but the lessons taught thereby are not of prime importance, and the cost of such an exhibition would be excessively expensive, - quite out of proportion to the value of the results. The scientific or technologic classification is all that remains, and this has yet to be developed.

Will the editor of Science indulge me in one more remark, as a corollary to what I have said?

There is a science of anthropology, composed of subsidiary sciences, which I group as follows : the biology of man, which is the study of the animal man, aud may be considered as belonging to biology proper, or anthropology; there is a science of psychology, which is a part of anthropology ; there is a science of technology, which includes all the arts of mankind; there is a science of sociology, which includes all the institutions of mankind; there is a science of philology, which includes the languages of mankind; and there is a science of philosophy, which includes the opinions of mankind; but there is no science of ethnology, for the attempt to classify mankind in groups has failed on every hand. Perhaps the most distinctive group of men yet discovered in the world are the Eskimos. They have in a general way physical characteristics which separate them from other peoples, but these distinctions fade out on the western coast of America and eastern coast of Asia They have arts peculiar to an arctic habitat, but their arts are not exclusively their own. Their institutions are yet practically unknown. Their opinions, as represented in their mythologies, are imperfectly known, but they yet furnish no characteristics by which they can be segregated from many other peoples; and Mr. Dall has shown that their languages are not wholly unconnected with other languages of the north. But when the attempt is made to set up other races in the world, it wholly fails. The unity of mankind is the greatest induction of anthropology.

Washington, June 11.

J. W. Powell.

I have to say a few words in reply to Major Powell's criticism of my letter in Science of May 20. It will be seen that in regard to several points which are discussed in my letter of June 17, and Major Powell's letter of to-day, there is no difference of opinion between Major Powell and myself, as his remarks would imply.

Major Powell infers that my remarks refer to archeological collections of pre-Columbian peoples. If he will kindly look at the contents of my two letters, he will see that no mention has been made of such collections, but that we discussed the general question of studying and arranging ethnological ma- terial. The mere fact that we do not know to which tribes archeological specimens belong excludes them from our discussion, and demands a different kind of treatment. I fully agree with Major Powell's remarks on this subject, but venture to say that they do not belong to the question at issue.

A few words more on Major Powell's remarks on the classification of tribes and the alleged impossibility of arranging a tribal museum. The problem has. been solved by numerous museums, even much larger than the national museum. The ideal plan of their arrangement is to exhibit a full set of a representative of an ethnical group, and to show slight peculiarities in small special sets. Experience shows that this can be done with collections from all parts of the world without over-burdening the collection with duplicates, and without making artificial classifications - only by grouping the tribes according to ethnic similarities. Such groups are not at all intended to be classifications, as Major Powell infers in his remarks on this subject. The principal difference between the plan advocated by Major Powell and adopted by Professor Mason, and that of other museums, is, that the latter exhibit the individual phenomenon, while the former make classifications that are not founded on the phenomenon, but in the mind of the student.

New York, June 18.

\section{Small-pox hospitals.}

In your issue of the 20th of May I notice a statement concerning the peculiar effect of small-pox in the vicinity of hospitals for that disease. Some years ago, small-pox was local here, and upon the termination of the case the bedding was burned in the yard of the premises; and I am informed, that, in the direction in which the smoke was driven by the wind, several cases of small-pox developed, while the surrounding neighborhood was otherwise free from it.

Among our acclimated people this disease is more dreaded than yellow-fever. The people here are opposed to burning bedding of yellow-fever patients, but favor burying or sinking in the channel. Our atmosphere never being purified by frost, our reliance must be upon the winds to purify and disinfect. Here every thing rapidly decays, and passes away into the atmosphere.

Key West, June \%.

\section{The scientific swindler again.}

About six weeks ago a delightfully intelligent and amiable deaf-and-dumb man appeared in Pottsville, and was entertained hospitably by Mr. Bard Wells, late of the geological survey of Pennsylvania, to whom he gave some valuable books, and from whom he took some, also a compass. He left Pottsville suddenly without paying his hotel-bill.

About two weeks afterward he called at the office of the survey, in Philadelphia, after office-hours, and represented himself to the janitress as an assistant on the survey, sent by the assistant in charge of the office to get certain survey reports. Having no written order to show, he was refused admittance, and went away very angry.

I see that he has turned up at Syracuse. It is astonishing that the fellow can have managed to escape capture so long.
J. P. Lesley. 